\title{
MICAN, a new fluorophore for vital and non-vital staining of human cells
} \author{
Zsolt Nagya, ${ }^{\mathrm{a}}$, Miklós Nagy ${ }^{\mathrm{a}, 1}$, Alexandra Kiss ${ }^{\mathrm{b}}$, Dávid Rácz ${ }^{\mathrm{a}}$, Beatrix Barna ${ }^{\mathrm{b}}$, Péter Könczöl ${ }^{\mathrm{b}}$, Csaba Bankóc, Zsolt

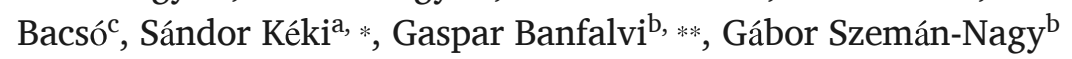 \\ a Department of Applied Chemistry, Faculty of Science, University of Debrecen, 4010, Hungary \\ ${ }^{\mathrm{b}}$ Department of Biotechnology and Microbiology, Faculty of Science, University of Debrecen, 4010, Hungary \\ ${ }^{c}$ University of Debrecen, Medical and Health Science Center, Faculty of Medicine, Department of Biophysics and Cell Biology, 4010, Hungary
}

\section{ARTICLE INFO}

\section{Keywords:}

Fluorescence imaging

Solvatochromism

Vital staining

Isocyanide

MICAN

\begin{abstract}
A B S T R A C T
Fluorescence time-lapse microscopy is in connection with the invasive properties of fluorochrome applied, and with the toxicity of the excitation energy and wavelength of the dye itself. Experiments with the newly synthesized fluorescent dye 1-N-methylamino-5-isocyanonaphthalene (MICAN) served to test its cytotoxicity on human HaCaT keratinocyte cell cultures. Experiments related to staining capability were performed with paraformaldehyde (PFA) fixed cells and observed with fluorescence microscope. It was assumed that the fluorophore 1-amino-5-isocyanonaphthalene (ICAN) and especially its N-methylamino derivative MICAN, containing condensed aromatic rings could serve as a nonselective fluorescent dye capable to stain cellular structures of fixed, living, damaged and dead cells. This notion was confirmed by the MICAN staining of cytoplasmic proteins primarily rough endoplasmic reticulum (RER), smooth endoplasmic reticulum (SEM) and less efficiently nuclear proteins suggesting the involvement of staining of subcellular structures involved in protein synthesis. MICAN was not only well tolerated by living cells but turned out to be a strong heterochromatin and RER staining agent. This led to the development of a MICAN staining protocol for native and living samples. Relative to other fluorescent dyes, MICAN is not only useful but also cost-effective. Toxicology tests were performed using $30,10,5,0.5 \mu \mathrm{g} / \mathrm{ml}$ MICAN concentrations. Time-lapse videomicroscopy at near-infrared (NIR) illumination has been used for the examination of MICAN effect on cell division. It was found that MICAN as a vital stain had no significant harmful effect on HaCaT cells. MICAN turned out to be a non-toxic, highly quantum-efficient vital stain with minimal, or no photobleaching, and can be applied to co-stain with propidium-iodide due the strong spectral separation.
\end{abstract}

\section{Introduction}

The synthesis of an effective solvatochromic fluorophore family was developed based on the basic compound 1-amino-5-isocyanonaphthalene (ICAN) and its derivative 1- $N$-methylamino-5-isocyanonaphthalene (MICAN) (Racz et al., 2014). MICAN was chosen over other derivatives because of its low reactivity relative to other ICAN members of this fluorophore family. The slow metabolism of MICAN in eukaryotic cells is accounted for by the presence of the methylamino group, that provides higher stability to perform long-term experiments versus other derivatives of ICAN. As none of the cell staining methods is perfect, there is a growing interest in new fluorescent substances that are taken up by cells without damaging them. This work deals: a) with the uptake of MICAN by the extracellular matrix, of HaCaT cells, b) determines the lowest toxic concentration where cells can still divide without detectable signs of apoptosis or necrosis and c) the emittance of sufficient fluorescence signals for the detection of the inner cell structure.

\section{Materials and methods}

\subsection{Synthesis of 1-N-methylamino-5-isocyanonaphthalene (MICAN)}

A $250 \mathrm{ml}$ round-bottomed flask containing 1-amino-5-isocyanonaphthalene $(1.00 \mathrm{~g}, 5.94 \mathrm{mmol})$, potassium hydroxide $(0.670 \mathrm{~g}, 11.9 \mathrm{mmol})$

* Correspondence to: S. Kéki, University of Debrecen, Department of Applied Chemistry, Hungary.

** Correspondence to: G. Banfalvi, University of Debrecen, Department of Biotechnology and Microbiology, Life Sciences Building 1.111, 1 Egyetem Square, Debrecen 4010, Hungary.

Email addresses: keki.sandor@science.unideb.hu (S. Kéki); gaspar.banfalvi@gmail.com (G. Banfalvi)

$1 \mathrm{ZN}$ and MN contributed equally to this work and are shared first authors. 
and dry dimethylformamide $(100 \mathrm{ml})$. The mixture was stirred with a magnetic bar. Methyliodide $(1.11 \mathrm{ml}, 17.8 \mathrm{mmol})$ was added to the solution, then the flask was flushed with argon and sealed with a rubber septum. The reaction mixture was stirred at room temperature in the dark to protect it from light. After 2 days $200 \mathrm{ml}$ methylene chloride and $5 \%$ ammonia solution was added, and the solution was extracted 5 times with water, then the organic phase was dried over anhydrous magnesium sulfate. The solvent was removed in a rotary evaporator and the residue was purified on a normal-phase silica gel filled column, using methylene chloride: hexane (1:1) as eluent. 1- $\mathrm{N}$-methylamino-5isocyanonaphthalene (MICAN) was obtained as yellow crystals (401 mg, 37\% yield).

ESI-MS: $m / z$ was measured to be 205.073 for $\left[\left(\mathrm{C}_{12} \mathrm{H}_{10} \mathrm{~N}_{2}\right)+\mathrm{Na}\right]^{+}$, versus the theoretical value of 205.074.

\subsection{NMR spectra}

The ${ }^{1} \mathrm{H}$ NMR and ${ }^{13} \mathrm{C}$ NMR spectra were measured at:

${ }^{1} \mathrm{H}$ NMR $\left(360 \mathrm{MHz}, \mathrm{CDCl}_{3}\right) \delta=7.83(\mathrm{~d}, J=8.5 \mathrm{~Hz}, 1 \mathrm{H}), 7.65-7.44$ (m, 3H), 7.35 (t, $J=8.0 \mathrm{~Hz}, 1 \mathrm{H}), 6.67(\mathrm{~s}, 1 \mathrm{H}), 4.52$ (s, 1H), 3.02 (s, 3H) $\mathrm{ppm}$.

${ }^{13} \mathrm{C}$ NMR $\left(91 \mathrm{MHz}, \mathrm{CDCl}_{3}\right) \delta=166.74\left(\mathrm{C}_{\mathrm{NC}}\right), 144.98\left(\mathrm{C}_{9,10}\right), 129.10$ $\left(\mathrm{C}_{2}\right), 124.58\left(\mathrm{C}_{4}\right), 123.65\left(\mathrm{C}_{1,5}\right), 123.36\left(\mathrm{C}_{8}\right), 121.82\left(\mathrm{C}_{7}\right), 111.64\left(\mathrm{C}_{6}\right)$, $105.11\left(\mathrm{C}_{3}\right), 30.99\left(\mathrm{C}_{\mathrm{CH} 3}\right)$ ppm. Supporting information as Figs. S1, S2.

\subsection{UV-visible spectroscopy}

The UV-visible spectra were recorded on an Agilent Cary 60 spectrophotometer (Agilent, Santa Clara, CA, USA) in a quartz cuvette of $1.00 \mathrm{~cm}$ optical length. $3.00 \mathrm{~cm}^{3}$ solution was prepared for each sample.

\subsection{Fluorescence measurements}

Steady-state fluorescence measurements were carried out using a Jasco FP-8200 fluorescence spectrophotometer equipped with a Xe lamp light source. The excitation and emission spectra were recorded at $20^{\circ} \mathrm{C}$, using $2.5 \mathrm{~nm}$ excitation, $5.0 \mathrm{~nm}$ emission bandwidth, and $200 \mathrm{~nm} / \mathrm{min}$ scanning speed. Fluorescence quantum yields were calculated by using quinine-sulfate in $0.1 \mathrm{~mol} / \mathrm{L}$ sulfuric acid as the reference absolute quantum efficiency $\left(\Phi_{\mathrm{n}}=55 \%\right)$.

For UV-visible and fluorescence measurements the investigated compounds were dissolved in acetonitrile at a concentration of $1.2 \mathrm{mM}$ and were diluted to $2.4 \times 10^{-5} \mathrm{M}$ and $4.7 \times 10^{-6} \mathrm{M}$, respectively in the solvents of interest. The spectra were processed using Spekwin32 software (Menges, 2015).

\subsection{Human cell lines}

The HaCaT cell line was derived from human skin, the cells spontaneously transformed in vitro during long time incubation (Boukamp et al., 1988, 1990). The human choroidal melanoma cell line OCM-1 cell line was obtained from the Research Center of Molecular Medicine, described as an aneuploid, near-tetraploid cell line (Kemeny-Beke et al., 2006). Human limbal (HuLi) cell line was established by Turani et al. (2014). Cells were cultured in RPMI-1640 medium (Sigma-Aldrich, Budapest, Hungary) containing 10\% fetal bovine serum (FBS, Hyclon, Logan, UT) and 1\% antibiotic-antimycotic mix (Penicillin-StreptomycinNeomycin).

\subsection{Fluorescent dyes}

Propidium Iodide (P4864, Sigma-Aldrich) has an excitation maximum of $535 \mathrm{~nm}$ and emission maximum of $617 \mathrm{~nm}$. Propidium iodide
(PI) binds to DNA by intercalating between the bases, with little or no sequence preference, and with a stoichiometry of one dye molecule per 4-5 base pairs of DNA.

Rhodamine B (83689, Sigma-Aldrich). The excitation maximum was found at $554 \mathrm{~nm}$, and emission maximum at $576 \mathrm{~nm}$. Rhodamine B similarly to MICAN is a nonspecific protein dye. Rhodamine B at $25 \mu \mathrm{g} / \mathrm{ml}$ and above significantly decreased the number of KD fibroblast cells after a $72 \mathrm{~h}$ culture (Kaji et al., 1991).

\subsection{Fixation and staining protocols}

The cells were cultured on microscope slides and fixed with 4\% PFA for $10 \mathrm{~min}$, and washed for $30 \mathrm{~min}$ in PBS, then dehydrated at $200^{\circ} \mathrm{C}$ (in a hot air sterilizer) for $15 \mathrm{~min}$. The staining was performed in a MICAN-DMSO solution at $2.4 \mu \mathrm{g} / \mathrm{ml}$ MICAN concentration. From the initial $0.5 \mathrm{mg} / \mathrm{ml}$ stock solution of MICAN, $400 \mu \mathrm{l}$ was completed to $1 \mathrm{ml}$ with DMSO. From this completed solution $36 \mu \mathrm{l}$ was taken and diluted with distilled water to $3 \mathrm{ml}$. This diluted MICAN solution $(2.4 \mu \mathrm{g} / \mathrm{ml})$ was used for the staining. Although, after the staining, the MICAN remained stable in the sample, but needed additional $30 \mathrm{~min}$ for binding. The nonpolar DMSO-MICAN treated samples were stable for weeks with a gradual increase of the fluorescent background.

\subsection{Incubation of cell culture in the presence of MICAN}

HaCaT cells in glass bottom dishes placed in a carbon dioxide incubator (SANYO MCO18-AC) at $37^{\circ} \mathrm{C}$ and $5 \% \mathrm{CO}_{2}$ were grown in RPMI1640 medium containing different concentrations of MICAN $(0.5,5$, 10 , and $30 \mu \mathrm{g} / \mathrm{ml})$ in DMSO: final volume $1 \%(\mathrm{v} / \mathrm{v})$. The medium was removed after $24 \mathrm{~h}$ incubation and washed three times with PBS. Then the samples were dried and fixed with 4\% PFA, then subjected to cross staining. HaCaT cells for LSC were incubated in open $\mu$-Slide (chambered coverslip) with 4 wells.

\subsection{Cross staining}

i) MICAN and Rhodamine B. For prefixed cell staining, $0.05 \mathrm{mg} / \mathrm{ml}$ Rhodamine B and $2.4 \mu \mathrm{g} / \mathrm{ml}$ aqueous solution of MICAN in 4:6 ratio were mixed, and used $10 \mu \mathrm{l}$ per slide.

ii) MICAN and PI cross staining. For prefixed cell staining, $0.05 \mathrm{mg} / \mathrm{ml}$ PI and $2.4 \mu \mathrm{g} / \mathrm{ml}$ aqueous solution of the MICAN in 3:7 ratio were mixed, and used $10 \mu \mathrm{l}$ per slide.

\subsection{Time-lapse scanning (TLS) microscopy and image analysis}

A detailed description of time-lapse microscopy was given earlier (Nagy et al., 2013, 2014a, 2014b). The system of TLS microscopy consists of: Four inverse microscopes (Olympus Tokyo) installed inside the $\mathrm{CO}_{2}$ incubator (SANYO MCO18-AC). Microscopes were modified for inverted usage as revolver turrets were transferred to the place of the original illumination. Diodes emitting light at $940 \mathrm{~nm}$ (LED: $5 \mathrm{~mm}$ in diameter; $1.2 \mathrm{~V}, 50 \mathrm{~mA}$, driven at $5 \mathrm{~V}$ using a serial $82 \mathrm{Ohm}$ resistor) were used to illuminate cells while minimizing heat and phototoxicity. The $940 \mathrm{~nm}$ wavelength turned out to be an acceptable compromise to avoid phototoxicity and to maintain sufficient resolution power. Plan achromatic objectives ( $\times 10$ : 0.25 NA) (Carl Zeiss Jena, Germany)) were used to enable a broad field of view to be imaged. Custom-modified 2 megapixel UVC camera (Asus Computer International, Fremont, CA, USA) boards with USB 2.0 connection served image detection. Cell cultures in glass bottom dish were placed under inverse microscopes, and photographs of cells were taken every minute. Ten images were collected, each within a $5 \mathrm{~s}$ interval and averaged to minimize noise. The 
collection of images within $5 \mathrm{~s}$ intervals was regarded as optimal time resolution.

\subsection{Image analysis}

National Health Institute's ImageJ software was used to analyze the image sequences of the time-lapse videomicroscopy (https://fiji.sc).

The image analyzing method included:

a) Image restoration and noise reduction:

- RGB image sequences were converted to 8-bit grayscale images. Deflickering by using a sequence stack histogram served to avoid transient brightness changes between separate frames. Contrast and brightness were equalized based on the stack (sequence) histogram at $0.4 \%$ of the pixels saturated.

- Fast Fourier-transformation and background subtraction: The background was reduced by bandpass filtering to exclude large structures down to 40 pixels and filtering small structures up to 3 pixels in size, and background extraction process using a rolling ball at a radius of 50 pixels.

b) Segmentation: Image sequences were thresholded using a stack histogram by keeping the information containing elements of the image sequence as foreground, and throwing the redundant pixels away by thresholding them into the background.

c) Measurement: Thresholding results in a binary image were used for graphical representation.

\subsection{Fluorescence microscopy}

The Carl Zeiss Photomicroscope II was used, with UV illuminating light produced by the XBO (150W/1) vapor lamp. Filters are widely used for DAPI excitation, BP (band pass) at $395-440 \mathrm{~nm}$, emission filter LP (long pass) at $470 \mathrm{~nm}$ and FITC excitation (BP 485/20, emission LP $515 \mathrm{~nm}$ ) filter. Filters used for propidium iodide (PI) staining consisted of 510-560 nm excitation filter, and LP $590 \mathrm{~nm}$ emission filter. Filters used for PI-MICAN cross-staining were the BP filter at $395-440 \mathrm{~nm}$ excitation and LP filter at $515 \mathrm{~nm}$ emission. The objectives of the microscope were: neofluar 100/1.30 oil immersion, neofluar $40 / 0.75$ and PLAN APO 63/1.4 oil immersion objectives.

\subsection{Laser-scanning imaging cytometry}

Laser-scanning microscopy was used for fluorescent live-cell imaging with parallel fluorescent detection of cell death. The iCys imaging system is based on an Olympus IX-71 inverted microscope equipped with four lasers, two photodiodes for chromatic absorbance detection and four photomultipliers for fluorescence detection. Scanning of the samples by laser beams took place point by point. During the scan, a fixed offset from the bottom of the coverslip was applied, which placed the focus to the middle plane of the cells. User-defined areas in the specimen with optimal cell density were marked as regions of interest (ROIs) and scanned in an automated manner. For video recording, each ROI was set to one scanning field $(1024 \times 768$ pixels $)$ and scanned multiple consecutive times by focused laser beams via an oscillating mirror in the $y$-direction and by the motorized stage in the $\mathrm{x}$-direction with a step size of $0.5 \mu \mathrm{m}$. The arising fluorescence signals were collected by a $40 \times$ LWD (NA 0.6) objective into two detection channels. PMT settings for the green channel were $36 \mathrm{~V}$, the gain was $100 \%$ and the offset was $-0.35 \mathrm{~V}$. In the long red channel, PMT was set to $40 \mathrm{~V}$, the gain to $100 \%$ and the offset to $-0.15 \mathrm{~V}$. PMT signals were converted into 14 bitpixel high-resolution images. For LSC imaging, a slide-based laserscanning iCys Research Imaging Cytometer (Thorlabs Imaging Systems, Sterling, VA) was used. Room temperature was used for the induction of slow cellular damage to estimate the applicability of parallel viability test. MICAN was added to the cells in $0.5 \mu \mathrm{g} / \mathrm{ml}$ final concentration and cell viability was tested by propidium iodide (PI, $5 \mu \mathrm{g} / \mathrm{ml}$ ) Images were made in eighty consecutive scanning cycles in $220 \mathrm{~s}$ intervals ( 3 min $40 \mathrm{~s}$ ) covering the time period of $5 \mathrm{~h}$. The movie was produced using fluorescence still images playing at an approximated 3000 times faster than the recording. MICAN was excited at $405 \mathrm{~nm}$ by a violet solid-state laser $(0.71 \mathrm{~mW}$ at turret), while PI was excited at $488 \mathrm{~nm}$ by a blue diode laser (turret intensity: $0.68 \mathrm{~mW}$ ). Fluorescence emission was detected with a band-pass filter at $530 \pm 30 \mathrm{~nm}$ and with a longpass filter above $650 \mathrm{~nm}$, respectively. Meanwhile, IR-TLS and toxicology tests were performed to prove that $\mathrm{HaCaT}$ cells tolerated much higher MICAN concentration $(5 \mu \mathrm{g} / \mathrm{ml})$ as well (Nagy et al., 2017).

\section{Results and discussion \\ 3.1. Spectral properties of MICAN}

The scope of the current work was to investigate MICAN, the Nmethylamino derivative of fluorophore 1 -amino-5-isocyanonaphthalene (ICAN). MICAN turned out to be an unspecific solvatochromic dye. MICAN contains an electron accepting and an electron donating group. The careful selection of these groups was important during its synthesis since the charge distribution between them gave rise to unique fluorescence properties and also extended the scope of applicability under vital and nonvital conditions. During the design of the fluorophore, two important aspects have been taken into consideration:

1. The dye contains a free hydrogen $(\mathrm{H})$ atom covalently bound to a highly electronegative atom such as nitrogen $(-\mathrm{NH})$ or oxygen $(-$ $\mathrm{OH}$ ) that perceives the electrostatic field of another electronegative atom and interacts with another organic molecule capable of forming hydrogen bonds.

The electron donor capability of the amino group of ICAN has been enhanced through alkylation which in turn resulted in the improvement of optical properties.

After these requirements were met, and 1- $\mathrm{N}$-methylamino-5-isocyanonaphthalene (MICAN) was synthesized, first the optical properties were investigated. Selected UV-visible and fluorescence spectra of MICAN are presented in Fig. 1. Additionally, the optical properties are summarized in Table 1, whereas all other spectra are presented in the supporting information (Figs. S3-S4).

Fig. 1 shows that MICAN has a low energy absorption band with a maximum near $365 \mathrm{~nm}$ close to the emission maximum of a regular $\mathrm{Hg}$ -

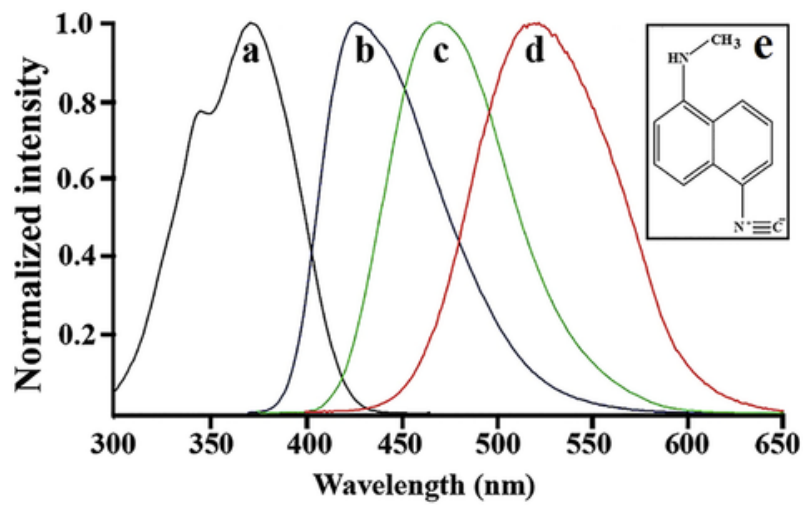

Fig. 1. Normalized absorption and emission spectra of MICAN. a) Absorption spec trum of MICAN. Emission spectra of MICAN: b) in hexane, c) in THF and d) in water, respectively. e) Inset shows the structure of MICAN. All spectra were recorded at $20^{\circ} \mathrm{C}$ and at concentration of $4.7 \times 10^{-6} \mathrm{M}$. 
Table 1

Emission $\left(\lambda_{\mathrm{em}}\right)$, excitation $\left(\lambda_{\mathrm{ex}}\right)$ maxima, Stokes shift $(\Delta \nu)$, molar extinction coefficient $(\varepsilon)$ and quantum yield ( $\left.\Phi_{\mathrm{F}}\right)$ of MICAN in different solvents.

\begin{tabular}{|c|c|c|c|c|c|c|}
\hline Solvent & Polarity index & $\begin{array}{l}\lambda_{\mathrm{em}, \max } \\
(\mathrm{nm})\end{array}$ & $\begin{array}{l}\lambda_{\text {ex,max }} \\
(\mathrm{nm})\end{array}$ & $\begin{array}{l}\text { Stokes shift } \\
\left(\mathrm{cm}^{-1}\right)\end{array}$ & $\begin{array}{l}\varepsilon \\
\left(\mathrm{M}^{-1}\right)\end{array}$ & $\begin{array}{l}\varphi_{\mathrm{F}} \\
(\%)\end{array}$ \\
\hline Hexane & 0.0 & 427 & 362 & 4205 & 8121 & 22 \\
\hline Toluene & 2.4 & 451 & 366 & 5149 & 7753 & 59 \\
\hline Dichloromethane & 3.1 & 470 & 368 & 5897 & 9154 & 65 \\
\hline i-Propanol & 3.9 & 491 & 372 & 6515 & & 63 \\
\hline THF & 4.0 & 470 & 371 & 5678 & 8102 & 64 \\
\hline Chloroform & 4.1 & 466 & 368 & 5715 & 8009 & 50 \\
\hline Ethyl acetate & 4.4 & 469 & 369 & 5778 & 7253 & 52 \\
\hline Dioxane & 4.8 & 464 & 369 & 5549 & 7376 & 85 \\
\hline Acetone & 5.1 & 483 & 372 & 6178 & 7822 & 44 \\
\hline Methanol & 5.1 & 493 & 371 & 6670 & 7891 & 41 \\
\hline Pyridine & 5.3 & 487 & 377 & 5991 & 8120 & 27 \\
\hline Acetonitrile & 5.8 & 490 & 370 & 6619 & 8156 & 50 \\
\hline Dimethyl formamide & 6.4 & 492 & 376 & 6271 & 8357 & 71 \\
\hline Dimethyl sulfoxide & 7.2 & 501 & 378 & 6495 & 8570 & 70 \\
\hline Water & 9.0 & 521 & 344 & 9876 & 7536 & 7 \\
\hline
\end{tabular}

vapor lamp used in fluorescence microscopes. In addition, MICAN has a considerable absorption at $405 \mathrm{~nm}$ and can also be excited with a $405 \mathrm{~nm}$ blue laser. The large dipole of the molecule results in a $94 \mathrm{~nm}$ shift in $\lambda_{\mathrm{em} \text {, max }}$ (from hexane to water), indicating that MICAN is highly sensitive to its chemical environment. The quantum yields are higher in solvents of low- or no polarity, and low in water, generating a negligible background emission in aqueous environment advantageous for the staining of living cells. To quantitatively describe the solvent-dependent behavior of MICAN the recent Catalán model was applied based on the following equation:

$$
\mathrm{Y}=\mathrm{Y}_{0}+\mathrm{aSA}+\mathrm{bSB}+\mathrm{sSP}+\mathrm{tSdP}
$$

where $\mathrm{Y}$ is the solvent effect, $\mathrm{Y}_{0}$ is the property of the substance of interest (e.g., emission maximum and Stokes shift) in the absence of solvent, for example, in the gas phase. SA is the quantitative empirical measure of the ability of bulk solvent to act as a hydrogen-bond donor towards a solute. SB is the quantitative empirical measure of the ability of a bulk solvent to act as a hydrogen-bond acceptor or electron-pair donor towards a solute, forming a solute-to-solvent hydrogen bond or a solvent-to-solute coordinative bond, respectively. SP and SdP are the solvent polarizability and dipolar parameters, respectively, determined using reference dye molecules. $a, b, s$ and $t$ are the corresponding coefficients and their inclusion in the equation indicates the dependence of the property under investigation upon the respective solvent parameter.

The Catalán coefficients for the emission wavenumber at the maximum $\left(\bar{\nu}_{\text {em,max }}\right)$ were obtained by multilinear regression analysis and are presented in Fig. 2.

The inset of Fig. 2 shows that the polarity of the solvent has the largest effect on the solvatochromic behavior. Both the H-bond donating and accepting capabilities of MICAN are pronounced (large capital $\mathrm{A}$ and $\mathrm{B}$ parameters) because of the presence of the free imino $(-\mathrm{NH})$ hydrogen (H-bond donor) and the isocyanide (isonitrile $-\mathrm{N} \equiv \mathrm{C}$ group) as (H-bond acceptor). The strong tendency of MICAN to form $\mathrm{H}$ bonds has implications with respect to its biological applications.

\subsection{Staining of HaCaT cells with MICAN}

Fig. 3. demonstrates the staining pattern of MICAN under different staining conditions. To test the fluorescent properties of MICAN, FITC and DAPI filters were used for fluorescence microscopy. Microscopic photos were taken with DAPI filter to prove that MICAN as a fluorescent dye acted similarly to DAPI and could be a useful stain for fluores-

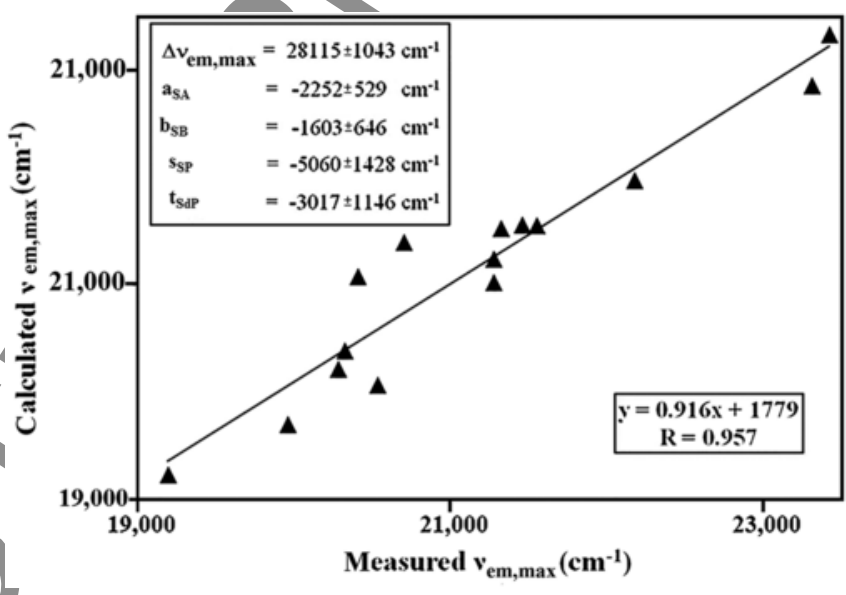

ig. 2. Plots of the measured and calculated emission maxima for MICAN obtained by the Catalán equation. Inset: solvent-independent correlation coefficients $\mathrm{a}_{\mathrm{SA}}, \mathrm{b}_{\mathrm{SB}}, \mathrm{s}_{\mathrm{SP}}$ and $\mathrm{t}_{\mathrm{SdP}}$ of the Catalán parameters SA, SB, SP and SdP, respectively. Solute property of the ref erence system $\left(\bar{\nu}_{\mathrm{em}, \max }\right)_{0}$, obtained by multiregression analysis. The corresponding SA, SB, SP and SdP values of the solvents have been described (Catalán, 2009).

cence microscopy either with FITC (Fig. 3a) or DAPI (Fig. 3b) filters. Higher accumulation of the fluorescent MICAN was observed around the outer surface of the cell membrane and moderate staining of the nucleus, but not to its double membrane, pointing to the binding of MICAN to proteins (Rácz et al., 2013).

\subsection{Cross staining of MICAN with rhodamine B}

To determine the main cellular target of MICAN, cross staining was performed with and without the xanthene dye rhodamine $\mathrm{B}$. The excitation maximum of rhodamine $B$ is $554 \mathrm{~nm}$, and its emission maximum $576 \mathrm{~nm}$. Rhodamine B has been listed as a specific stain for cornification (Liisberg, 1968) and used for the identification of keratin (Delescluse et al., 1976; Pinkus et al., 1980). Fig. 3c shows the staining of HaCaT keratinocytes with MICAN under the staining conditions of rhodamine B. Fig. 3d comprises the co-staining of MICAN and rhodamine $B$. Due to the high reactivity of rhodamine compounds, rhodamine B reacts with specific groups of proteins e.g. sulfhydryl groups of amino acids, likely to impact thiol-disulfide exchange mechanisms of redox active thiol groups inside cells. The similarity between the staining of MICAN and rhodamine B indicated that MICAN stained cells also in a nonselective manner. 

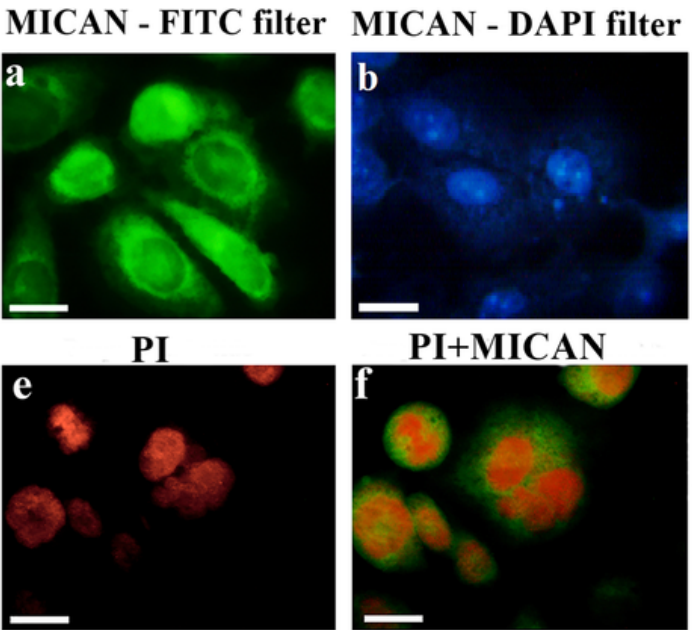

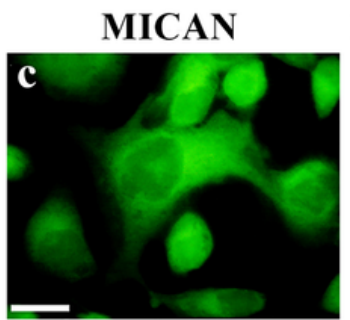

MICAN+Rhodamin B
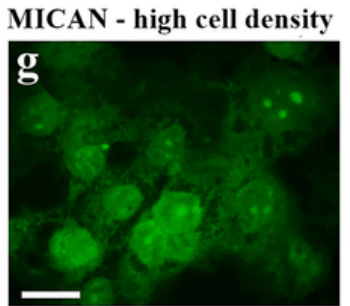

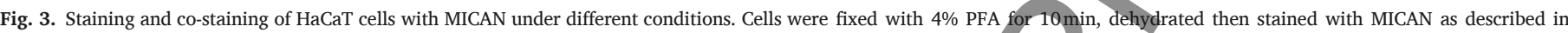

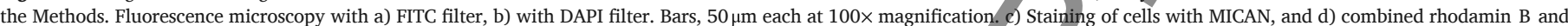

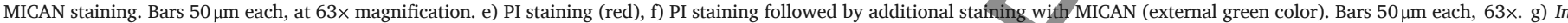

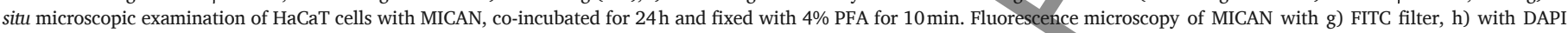
filter. Bars, $50 \mu \mathrm{m}$ each at $100 \times$ magnification. (For interpretation of the references to color in this figure legend, the reader is referred to the web version of this article.)

\subsection{Consecutive staining of propidium iodide and MICAN}

Additive staining of HaCaT cells was performed with propidium iodide (PI) followed by MICAN exposure. PI is a selective nuclear dye. PI excitation maximum was found at $535 \mathrm{~nm}$, and the emission maximum at $617 \mathrm{~nm}$. We used FITC long pass filter to see the fluorescent emissions of these dyes. The idea of co-staining of MICAN with PI was based on the assumption that MICAN is compatible with nonacidic cell dyes, due to the instability of its isocyanide functional group in acidic medium. Fig. 3e shows the staining of paraformaldehyde (PFA) prefixed HaCaT cells with PI alone and after additional staining with MICAN (Fig. 3f). Post-staining proved the affinity of MICAN to proteins located in subcellar structures around the nucleus such as rough and smooth endoplasmic reticulum (RER, and SER). This combination of staining also revealed that MICAN was bound poorly to the nuclear matrix since it was likely to be excluded by the nuclear envelope.

\subsection{MICAN staining at different densities of HaCaT cells}

When live cells were co-incubated with the fluorescent MICAN, the dye was found to penetrate into cells, unless they were prepared as PFA fixed denatured samples. It was found that MICAN is binding to proteins present in the cell culture medium, primarily to BSA (Rácz et al., 2013). Due to the nonpolar character of MICAN the non-covalent hydrogen bonded protein-MICAN complex could penetrate into cells by vesicular transport. Such adduct (complex) formation for ICAN deriva- tives was previously proven by fluorescence spectroscopy (Nagy et al., 2016). The processing of fluorescent images revealed significant differences between stained and coincubated cells. The PFA fixed, and MICAN stained samples showed characteristic binding to cytoplasmic proteins primarily to RER and DER and a lower binding to spots of nuclear proteins. It deserves notice that inside the nucleus, the heterochromatin dynamics generates compact spots with high fluorescent intensity (Ueda et al., 2014; Wreggett et al., 1994; Ishov et al., 2004). MICAN staining favored by nonpolar conditions inside the cells could be the reason why concentrated spots in the nucleus became visible. Methylated histones contributing to the nonpolar character of nuclear structures could explain the selectivity of MICAN binding to heterochromatin structures in the nucleus of living cells. Living HaCaT cells subjected to MICAN staining show the intrusion of dye into cells (Fig. $3 g, h)$.

\subsection{Uptake of MICAN by cells}

The aqueous environment for MICAN was provided by the presence of DMSO, which under cell culture conditions was tolerated up to $1 \%$ ( $/ \mathrm{v})$. MICAN binds first to the proteins of the medium primarily to BSA (Nagy et al., 2016). Cells take up labeled proteins with endosomal or vesicular ingestion, transport and release them into the lumen of RER (Cooper, 2000; Pfeffer and Rothman, 1987; Le Borgne and Hoflack, 1998). The MICAN-protein binding is beneficial in the sense that the uptake of MICAN is alleviated by DMSO containing medium, despite the poor solubility of MICAN in water (Table 2).

Table 2

HaCaT cell monolayer confluency changes upon DMSO and MICAN treatment.

\begin{tabular}{|c|c|c|c|c|c|}
\hline Time-lapse microscopy & DMSO v/v \% & MICAN $\mu \mathrm{g} / \mathrm{ml}$ & Conflu & & \\
\hline & & & Initial & Relapsed to & Final \\
\hline 1 & 0 & 0 & 38 & 37.9 & 100 \\
\hline 2 & 1 & 0 & 37 & 36.8 & 79.9 \\
\hline 3 & 1 & 0,5 & 40 & 26.1 & 66.6 \\
\hline 4 & 1 & 5 & 40 & 16.0 & 65.2 \\
\hline 5 & 1 & 10 & 40 & 23.2 & 66.0 \\
\hline 6 & 1 & 30 & 40 & 20.7 & 0 \\
\hline
\end{tabular}




\subsection{Toxicity of MICAN to HaCaT cell culture}

Experiments were undertaken using the HaCaT cell culture at different concentrations of MICAN with an initial confluence of nearly $40 \%$. Four MICAN concentrations were tested: $0.5,5,10$ and $30 \mu \mathrm{g} / \mathrm{ml}$. The monitoring of growth of monolayer cultures in the presence of MICAN lasted for $24 \mathrm{~h}$. Alterations in the growth of the monolayer were followed by time-lapse microphotography and image analysis (Fig. 4). Experiments were performed in glass bottom dishes.

Corresponding to expectations, control cells grew faster and reached confluency in $24 \mathrm{~h}$, whereas the lower growth rate in the presence of DMSO resulted in a plateau phase at $80 \%$ confluence (Fig. 4). This finding is in agreement with the observations of others (Timm et al., 2013; Forman et al., 1999; Hollebeeck et al., 2011) who found that DMSO above $1 \%$ reduced the readout parameters in different cell types, thus the DMSO solvent concentration was kept constant in the serial dilution of MICAN investigations.

Relative to the two control experiments in the absence and presence of $1 \%$ DMSO, treatment with MICAN containing 1\% DMSO moderately impacted cell growth and the formation of the monolayer. In each used MICAN concentration cell clusters shrank and individual cells became rounded up, but kept their viability and increasingly more time was needed for cell cultures to continue growth at elevated MICAN concentrations. The growth curves in (Fig. 5) at 0.5 and $5 \mu \mathrm{g} / \mathrm{ml}$ MICAN concentrations clearly show an initial decrease in the monolayer surface area, followed by the re-growth of surface area covered by the cells (Fig. 5). Typically the shape of $60-80 \%$ of $\mathrm{HaCaT}$ cells was impacted by MICAN in the examined microscopic field. Similar observations were made with human OCM-1 and HuLi cells (not shown). That the viability of HaCaT cells in the presence of $0.5 \mu \mathrm{g} / \mathrm{ml} \mathrm{MICAN}$ is not impacted, is shown in the supplementary video presentation.

The rounding up of HaCaT cells was also observed at different (10 and $30 \mu \mathrm{g} / \mathrm{ml}$ ) MICAN concentrations (Fig. 6). The notable differences between the panels of growth curves at $10 \mu \mathrm{g} / \mathrm{ml}$ (Fig. 6 upper left curve) and $30 \mu \mathrm{g} / \mathrm{ml}$ MICAN concentrations (Fig. 6 upper right curve) indicate that the recovery of initial blockade of cell growth up to $10 \mu \mathrm{g} / \mathrm{ml}$ is contrasted by a temporary and virtual regrowth that is followed by the complete breakdown of proliferation at $30 \mu \mathrm{g} / \mathrm{ml}$ MICAN concentration. Details are given in Video S1

The upper left growth curve in Fig. 6 also shows that at $10 \mu \mathrm{g} / \mathrm{ml}$ MICAN concentration the curve can be divided into 3 phases: Temporary regression from $40 \%$ to $21 \%$ confluence $(0-2 \mathrm{~h})$. Recovery of cell growth (between 3 and $10 \mathrm{~h}$ ). Stationary phase of cell growth (after 12h). Time-lapse microscopy (Fig. 6 left bottom panels): even distribution of individual cells. At $30 \mu \mathrm{g} / \mathrm{ml}$ MICAN concentration (in Fig. 6) the growth curve can subdivided to: Regression of growth $(0-2 \mathrm{~h}), \mathrm{b})$ Temporary regrowth (2-8h), c) Death phase (8-15h), d) Complete loss of cell growth (after 15h). Time-lapse microscopy at $30 \mu \mathrm{g} / \mathrm{ml}$ MICAN concentration (Fig. 6 bottom right panels) clearly shows the aggregation of dead cells. Black number at the bottom of each panel shows the time of photomicrography.

The complete cessation of cell growth at the highest MICAN concentration $(30 \mu \mathrm{g} / \mathrm{ml})$ could be accounted for by the protracted penetration of DMSO-MICAN complex into the cells. A further conclusion that could be drawn from the penetration of the DMSO-dye complex was that the inhibition of cell growth was moderately reduced by the presence of DMSO alone could have been additive in the presence of MICAN. This observation is supported by the data showing the drastic relapse from the-initial $40 \%$ to $20 \%$ confluency.

Time-lapse laser-scanning microscopy at low excitation energy was used to collect 80 images within a 5 hour period as shown on Fig. 7 . and Supplementary Video S2. The progression of slow cellular death was followed by parallel PI staining. No cross-talk between the two fluorophore was observed during the experiment. Analysis of the acquired image sequences indicate low staining background and insignificant photobleaching of the MICAN resulting in a high signal/noise ratio
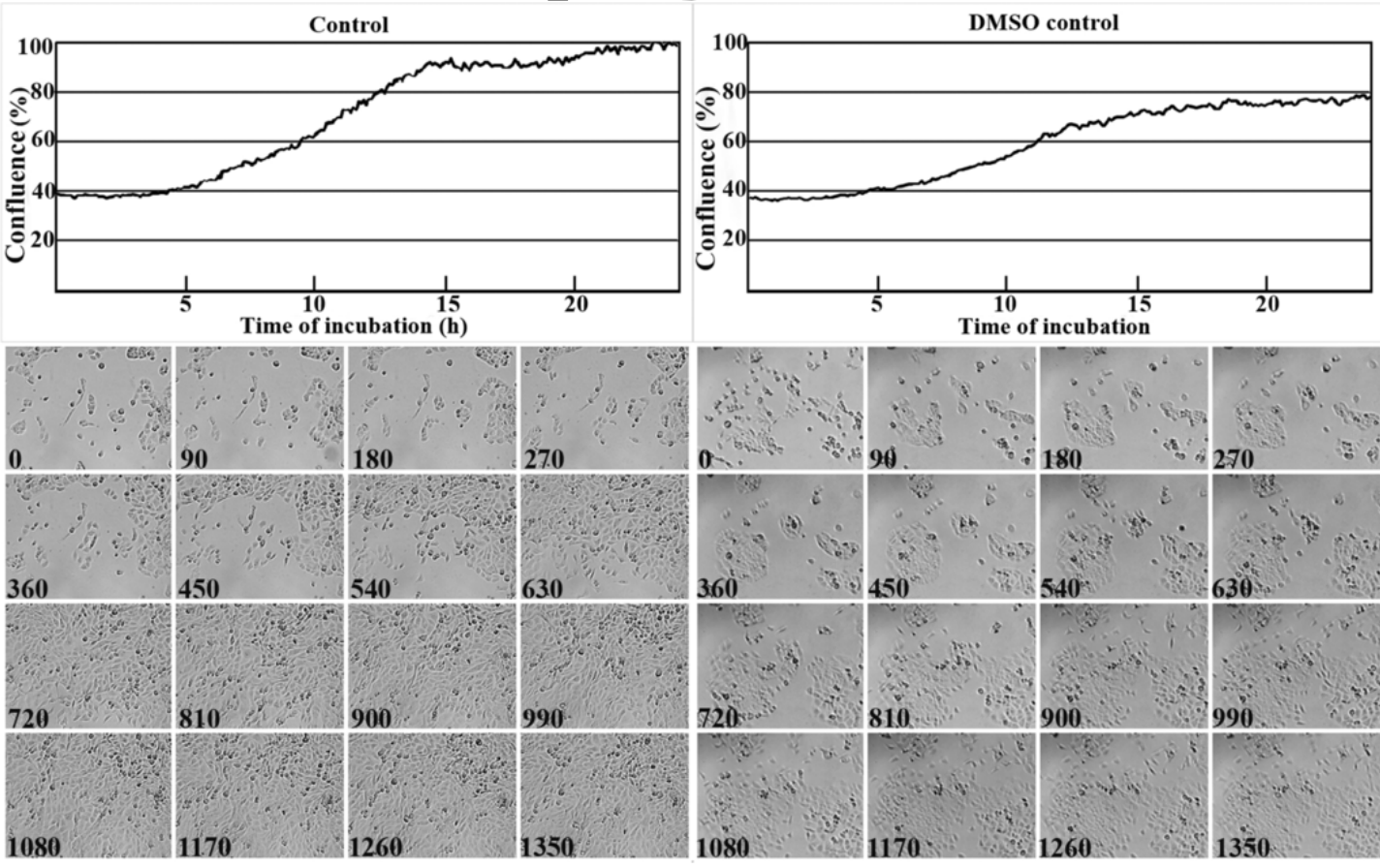

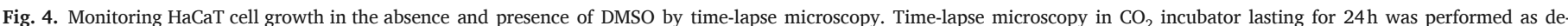

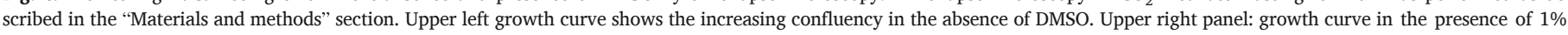

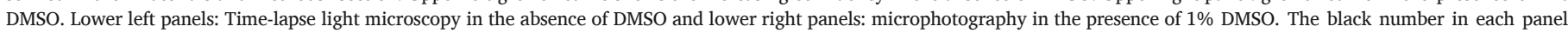
gives the time of microscopy in min. 

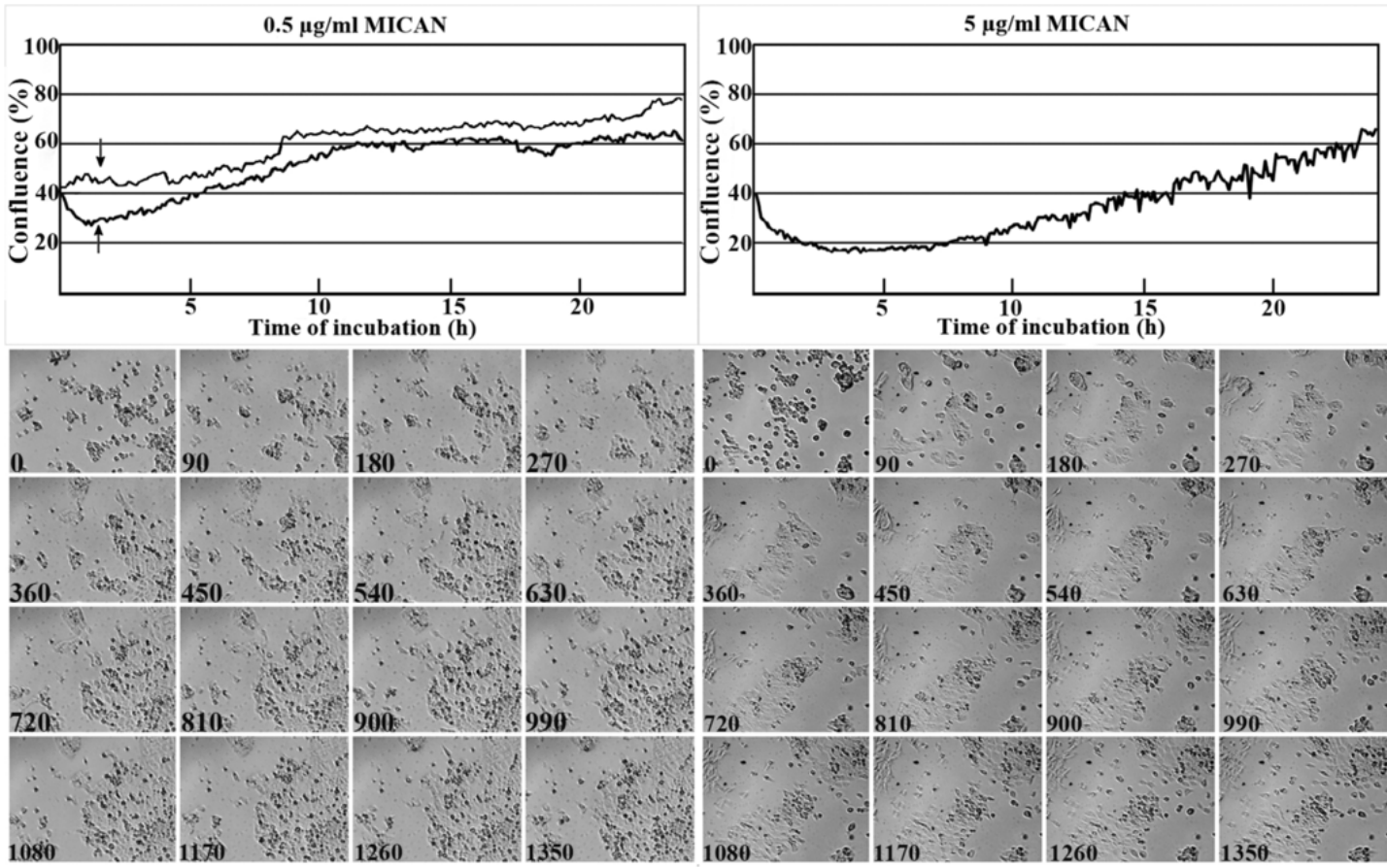

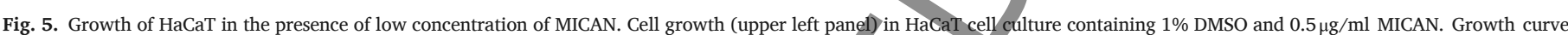
(upper right curve) and time-lapse microscopy in $1 \%$ DMSO at $5 \mu \mathrm{g} / \mathrm{ml}$ MICAN concentration. Black numbers in the lower panels indicate the time when the photographs were taken.
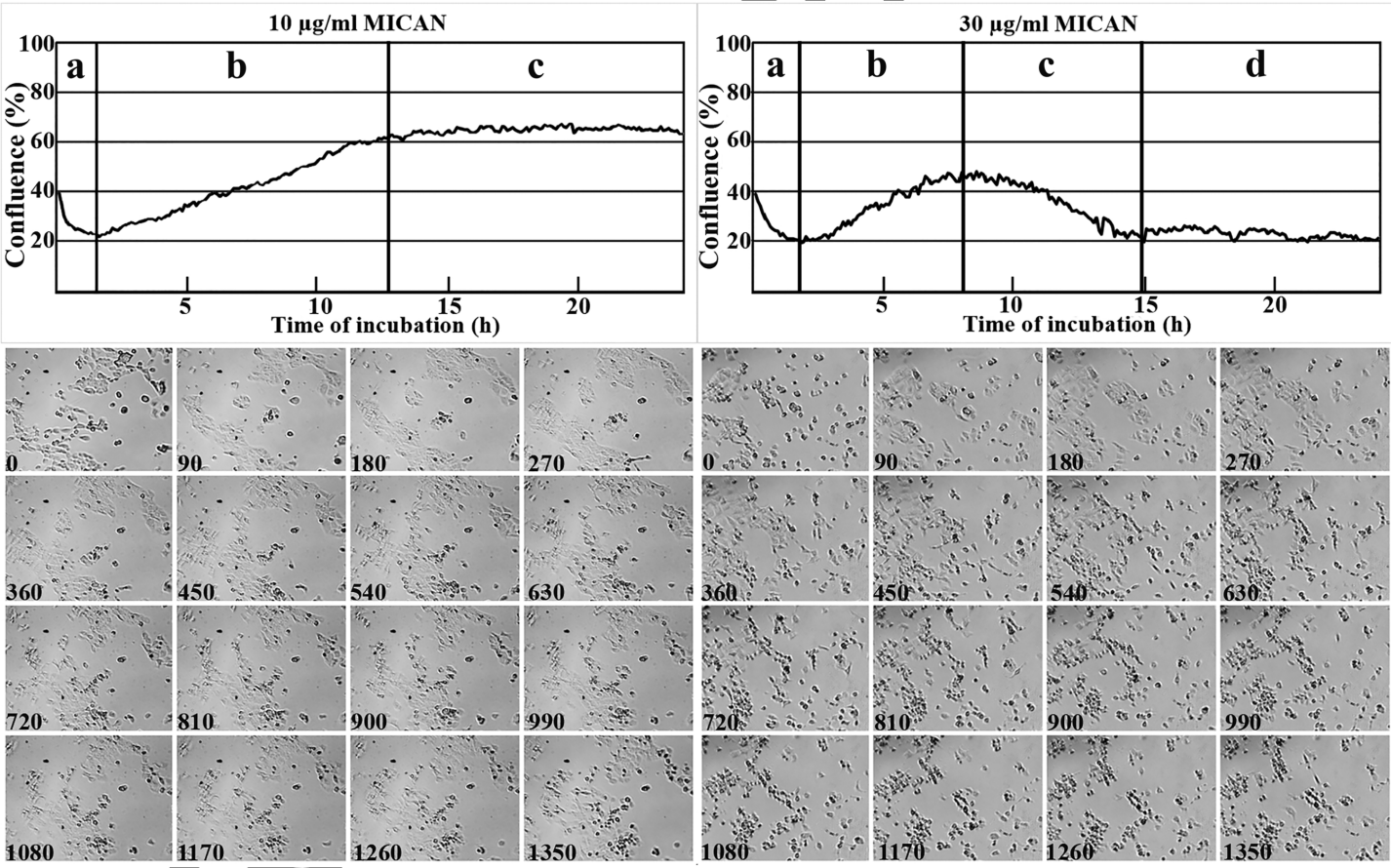

Fig. 6. Growth inhibition of HaCaT cells by MICAN at higher concentrations. The same experiment was carried out as under this figure at 10 and $30 \mu \mathrm{g} / \mathrm{ml}$ MICAN concentrations.

within the experimentalinterval as shown on the linear plots in Fig. 8. No phototoxicity was observed during the experiment.

Images of Figs. 7 and 8 taken from consecutive scanning cycles in 220 s intervals ( $3 \mathrm{~min} 40 \mathrm{~s}$ ) covering the time period of $5 \mathrm{~h}$ did not show any toxicity of MICAN. The video was produced using fluorescence images visualized 3000 times faster than the recording (Video S2).

\section{Conclusions}

The fluorophore MICAN molecule is applicable in cell staining practice both as a nonvital, and a vital dye. MICAN showed characteristic binding to cytoplasmic proteins primarily to RER and DER and a slight selectivity to spots of proteins in the nuclear heterochromatin or NOR regions. The compound is well tolerated by human cell cultures between 0.5 and $10 \mu \mathrm{g} / \mathrm{ml}$ concentrations. Furthermore, there is sufficient 


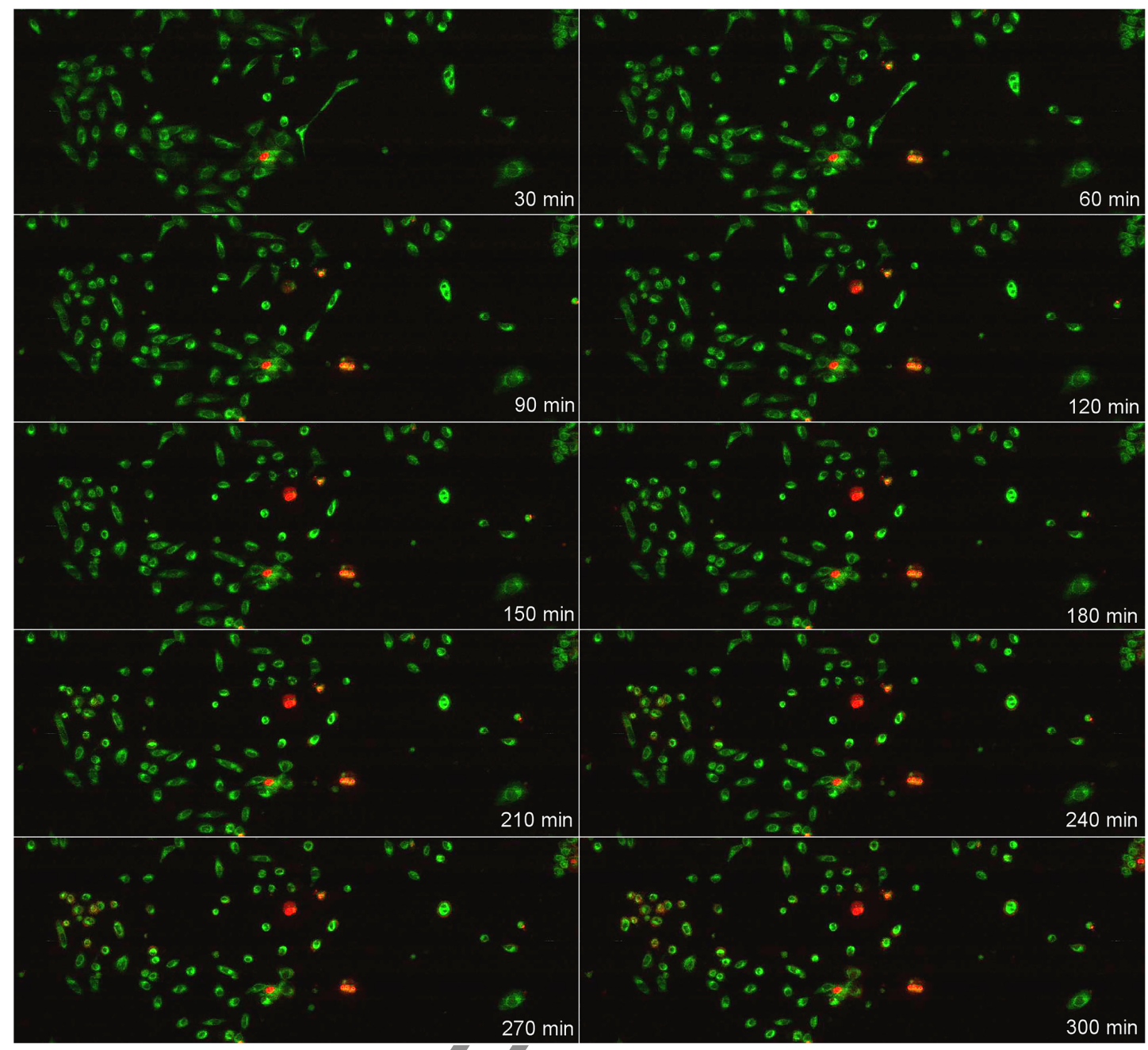

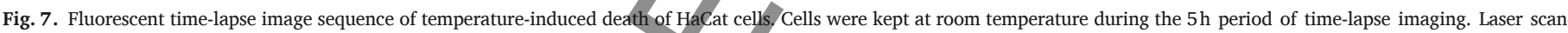

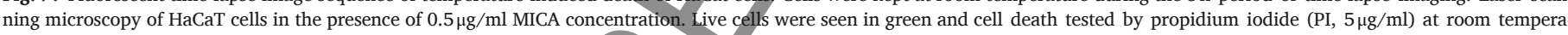

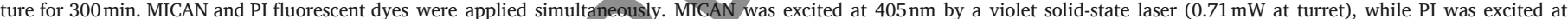

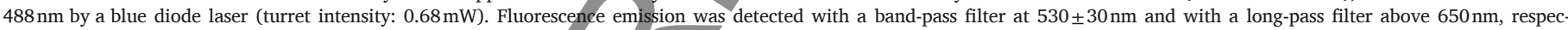

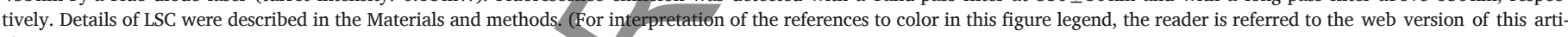
cle.)

intensity for fluorescence imaging in the nontoxic range between 0.5 and $10 \mu \mathrm{g} / \mathrm{ml}$ concentrations. The function of the cells is affected at higher concentrations when MICAN binds to proteins of the cell and modifies their function. Visible torsions in cells were observed in the $20-30 \mu \mathrm{g} / \mathrm{ml}$ MICAN concentration range. Nonspecific MICAN staining of cellular proteins allowed the long term tracking of subcellular processes by fluorescent time-lapse microscopy. According to fluorescent time-lapse microscopy investigations, MICAN showed spectral separation from PI offering a possible co-application of the two dyes. Within the $5 \mathrm{~h}$ of experiment no photobleaching was observed. Due to the high quantum efficiency of MICAN, the intensity of the excitatory fluorescent light could be reduced significantly, and minimized the major problem, namely the phototoxicity of time-lapse microscopy. Advantages of MICAN as a "Live-or-Die" dye can be summarized as:

- Minimal invasiveness: Low toxicity within the application range

- Stability: Minimal or negligible photobleaching

- Efficiency: High quantum-efficiency helping to reduce phototoxicity due excitation

- Affordable: Lower cost than commercial stains

- Choice: 8 bright colors across the spectrum

- Non-specific: Staining of live and dead cells
- Fixable: No loss of brightness after fixation

- Versatile: Applicable both for light and fluorescence microscopy

- Made by experts in dye chemistry in our university.

MICAN the promising new fluorescent dye and the first applicable derivative of ICAN is under further investigation involving chemical modification and biological characterization. Also, applicable concentrations of MICAN turned out to be nontoxic in vivo, based on preliminary animal experiments carried out in mice (Nagy et al., unpublished data).

Supplementary data to this article can be found online at https:// doi.org/10.1016/j.tiv.2018.01.012.

\section{Conflict of interest}

None declared.

\section{Uncited references}

Awtar, 1975

Khot et al., 2015

Kubin and Fletcher, 1983 


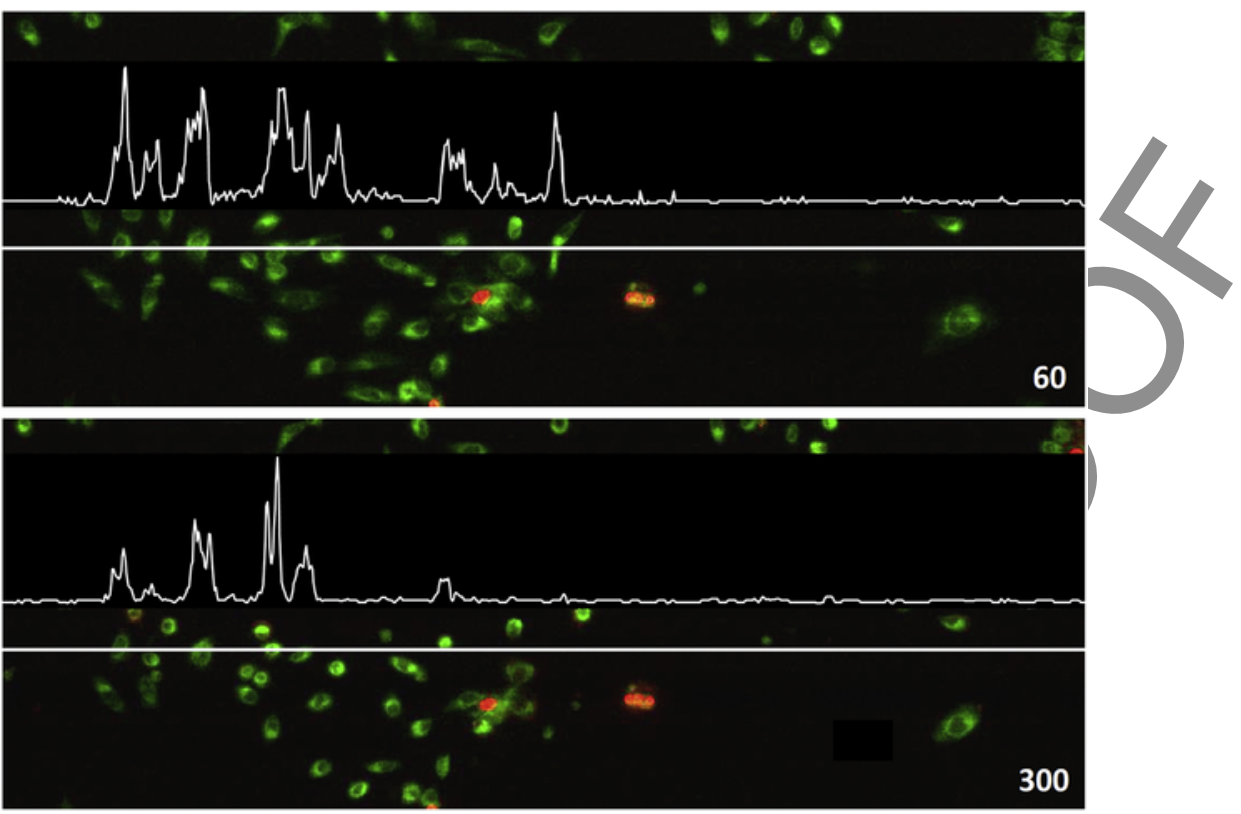

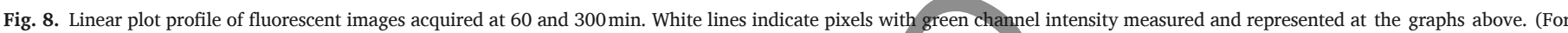
interpretation of the references to color in this figure legend, the reader is referred to the web version of this article.)

\section{Smith and Crocker, 1988}

\section{Acknowledgements}

This work was financially supported by the grants K-116465 and GINOP-2.3.2-15-2016-00041 provided by NFKI (National Research, Development and Innovation Office, Hungary) to SK. This paper was also supported by the János Bolyai Research Scholarship of the Hungarian Academy of Sciences to MN.

\section{References}

Awtar, K., 1975. Rapid flow cytofluorometric analysis of mammalian cell cycle by propidium iodide staining. J. Cell Biol. 66 (1), 188-193.

Boukamp, P., Petrusevska, R.T., Breitkreut, D., Hornung, J., Markham, A., Fusenig, N.E., 1988. Normal keratinization in a spontaneously immortalized aneuploid human keratinocyte line. J. Cell Biol. 106, 761-771.

Boukamp, P., Stanbridge, E.J., Foo, D.Y., Cerutti, P.A., Fusenig, N.E., 1990. c-Ha-ras oncogene expression in immortalized human keratinocytes (HaCaT) alters growth potential in vivo but lacks correlation with malignancy. Cancer Res. 50, 2840-2847.

Catalán, J., 2009. Toward a generalized treatment of the solvent effect based on four empirical scales: dipolarity (sdp, a New Scale), polarizability (SP), acidity (SA), and basicity (SB) of the medium. J. Phys. Chem. B 113 (17), 5951-5960.

Cooper, G.M., 2000. The Cell: A Molecular Approach, 2nd edition Sinauer Associates, Sunderland (MA)

Delescluse, C., Fukuyama, K., Epstein, W.L., 1976. Dibutyryl cyclic AMP-induced differentiation of epidermal cells in tissue culture. J. Invest. Derm. 66, 8-13.

Forman, S., Kás, J., Fini, F., Steinberg, M., Ruml, T., 1999. The effect of different solvents on the ATP/ADP content and growth properties of HeLa cells. J. Biochem. Mol. Toxicol. 13 (1), 11-15.

Hollebeeck, S., Raas, T., Piront, N., Schneider, Y.J., Toussaint, O., Larondelle, Y., During, A., 2011. Dimethyl sulfoxide (DMSO) attenuates the inflammatory response in the in vitro intestinal Caco-2 cell model. Toxicol. Lett. 206 (3), 268-275. https://doi.org/ 10.1016/j.toxlet.2011.08.010.

Ishov, A.M., Vladimirova, O.V., Maul, G.G., 2004. Heterochromatin and ND10 are cell-cycle regulated and phosphorylation-dependent alternate nuclear sites of the transcription repressor Daxx and SWI/SNF protein ATRX. J. Cell Sci. 117, 3807-3820. https: //doi.org/10.1242/jcs.01230.

Kaji, T., Kawashima, T., Sakamoto, M., Kurashige, Y., Koizumi, F., 1991. Inhibitory effect of rhodamine B on the proliferation of human lip fibroblasts in culture. Toxicology $68,11-20$.

Kemeny-Beke, A., Berenyi, E., Facsko, A., Damjanovich, J., Horvath, A., Bokor, A., Bodnar, A., Berta, A., Aradi, J., 2006. Antiproliretaive effect of 4-thyouridylate on OCM1 uveal melanoma cells. Eur. J. Ophthalmol. 16, 680-685.

Khot, K.P., Kotak, K.J., Bagri-Manjrekar, K., Alex, S., Choudhari, S.S., 2015. Pleomorphism of argyrophilic nucleolar organizer regions in oral submucous fibrosis and oral squamous cell carcinoma. J. Nat. Sci. Biol. Med. 6 (Suppl. 1), S35-S39.
Kubin, R.F., Fletcher, A.N., 1983. Fluorescence quantum yields of some rhodamine dyes J. Lumin. 27 (4), 455-462. https://doi.org/10.1016/0022-2313(82)90045-X.

Le Borgne, R., Hoflack, B., 1998. Protein transport from the secretory to the endocytic pathway in mammalian. Biochim. Biophys. Acta 1404 (1-2), 195-209.

Liisberg, M.F. 1968. Rhodamine B as an extremely specific stain for cornification. Cells Tissues Organs 69 (1), 52-57.

enges, F., 2015. Spekwin32-optical spectroscopy software, version 1.72.0. In: http:// www.efemm2.de/spekwin.

Nagy, G., Király, G., Turáni, M., Bánfalvi, G., 2013. Cell trivision of hyperploid cells. DNA Cell Biol. 32 (12), 676-684. https://doi.org/10.1089/dna.2013.2147.

Nagy, G., Hennig, G.W., Petrényi, K., Kovács, L., Pócsi, I., Dombrádi, V., Bánfalvi, G., 2014. Time-lapse video microscopy and image analysis of adherence and growth patterns of Candida albicans strains. Appl. Microbiol. Biotechnol. 98, 5185-5194. https: //doi.org/10.1007/s00253-014-5696-5.

Nagy, M., Rácz, D., Lázár, L., Purgel, M., Ditrói, T., Zsuga, M., Kéki, S., 2014. Solvatochromic study of highly fluorescent alkylated isocyanonaphthalenes, their p-stacking, hydrogen-bonding complexation, and quenching with pyridine. Chem. Phys. Chem. 15 (16), 3614-3625. https://doi.org/10.1002/cphc.201402310.

Nagy, M., Rácz, D., Nagy, Z.L., Nagym, T., Fehér, P.P., Purgel, M., Zsuga, M., Kéki, S., 2016. An acrylated isocyanonaphthalene based solvatochromic click reagent: optical and biolabeling properties and quantum chemical modeling. Dyes Pigments 133, 445-457. https://doi.org/10.1016/j.dyepig.2016.06.036.

Nagy, M., Rácz, D., Nagy, Z.L., Fehér, P.P., Kalmar, J., Fábián, I., Kiss, A., Zsuga, M., Kéki, S., 2017. Solvatochromic isocyanonaphthalene dyes as ligands for silver(I) com plexes, their applicability in silver(I) detection and background reduction in biolabelling. Sensors Actuators B(10 September 2017, In press).

Pfeffer, S.R., Rothman, J.E., 1987. Biosynthetic protein transport and sorting by the endoplasmic reticulum and golgi. Annu. Rev. Biochem. 56, 829-852. https://doi.org/10. 1146/annurev.bi.56.070187.004145.

Pinkus, H., Mehregan, A.H., Rahbari, H., Krobock, E., 1980. Rhodamin B stain for keratin: evaluation of its specificity and its application in dermal pathology. J. Cutan. Pathol. 7 (4), 222-226.

Rácz, D., Nagy, M., Mándi, A., Zsuga, M., Kéki, S., 2013. Solvatochromic properties of a new isocyanonaphthalene based fluorophore. J. Photochem. Photobiol. A Chem. 270 19-27. https://doi.org/10.1002/cphc.201402310.

Smith, R., Crocker, J., 1988. Evaluation of nucleolar organizer region-associated protein in breast malignancy. Histopathology 12 (2), 113-125.

Timm, M., Saaby, L., Moesby, L., Hansen, E.W., 2013. Considerations regarding use of solvents in in vitro cell based assays. Cytotechnology 65 (5), 887-894. https://doi. org/10.1007/s10616-012-9530-6.

Turani, M., Banfalvi, G., Peter, A., Kukoricza, K., Kiraly, G., Talas, L., Tancos, B., Balazs, D., Nagy, G., Kemeny-Beke, A., 2014. Antibiotics delay in vitro human stem cell regrowth. Toxicol. in Vitro 29 (2), 370-379. https://doi.org/10.1016/j.tiv.2014.10. 013.

Ueda, J., Maehara, K., Mashiko, D., Ichinose, T., Yao, T., Hori, M., Sato, Y., Kimura, H., Ohkawa, Y., Yamagata, K., 2014. Heterochromatin dynamics during the differentiation process revealed by the DNA methylation reporter mouse, methylRO. Stem Cell Rep. 2 (6), 910-924. https://doi.org/10.1016/j.stemcr.2014.05.008.

Wreggett, K.A., Hill, F., James, P.S., Hutchings, A., Butcher, G.W., Singh, P.B., 1994. A mammalian homologue of Drosophila heterochromatin protein 1 (HP1) is a component of constitutive heterochromatin. Cytogenet. Cell Genet. 66, 99-103. https://doi. org/10.1159/000133676. 
The rounding up of HaCaT cells was also observed at different (10 and $30 \mu \mathrm{g} / \mathrm{ml}$ ) MICAN concentrations (Fig. 6). The notable differences between the panels of growth curves at $10 \mu \mathrm{g} / \mathrm{ml}$ (Fig. 6 upper left curve) and $30 \mu \mathrm{g} / \mathrm{ml}$ MICAN concentrations (Fig. 6 upper right curve) indicate that the recovery of initial blockade of cell growth up to $10 \mu \mathrm{g} / \mathrm{ml}$ is contrasted by a temporary and virtual regrowth that is followed by the complete breakdown of proliferation at $30 \mu \mathrm{g} / \mathrm{ml}$ MICAN concentration. Details are given in Video S1.

Time-lapse laser-scanning microscopy at low excitation energy was used to collect 80 images within a 5 hour period as shown on Fig. 7. and Supplementary Video S2. The progression of slow cellular death was followed by parallel PI staining. No cross-talk between the two fluorophore was observed during the experiment. Analysis of the acquired image sequences indicate low staining background and insignificant photobleaching of the MICAN resulting in a high signal/noise ratio within the experimental interval as shown on the linear plots in Fig. 8. No phototoxicity was observed during the experiment.

Images of Figs. 7 and 8 taken from consecutive scanning cycles in $220 \mathrm{~s}$ intervals ( $3 \mathrm{~min} 40 \mathrm{~s}$ ) covering the time period of $5 \mathrm{~h}$ did not show any toxicity of MICAN. The video was produced using fluorescence images visualized 3000 times faster than the recording (Video S2).

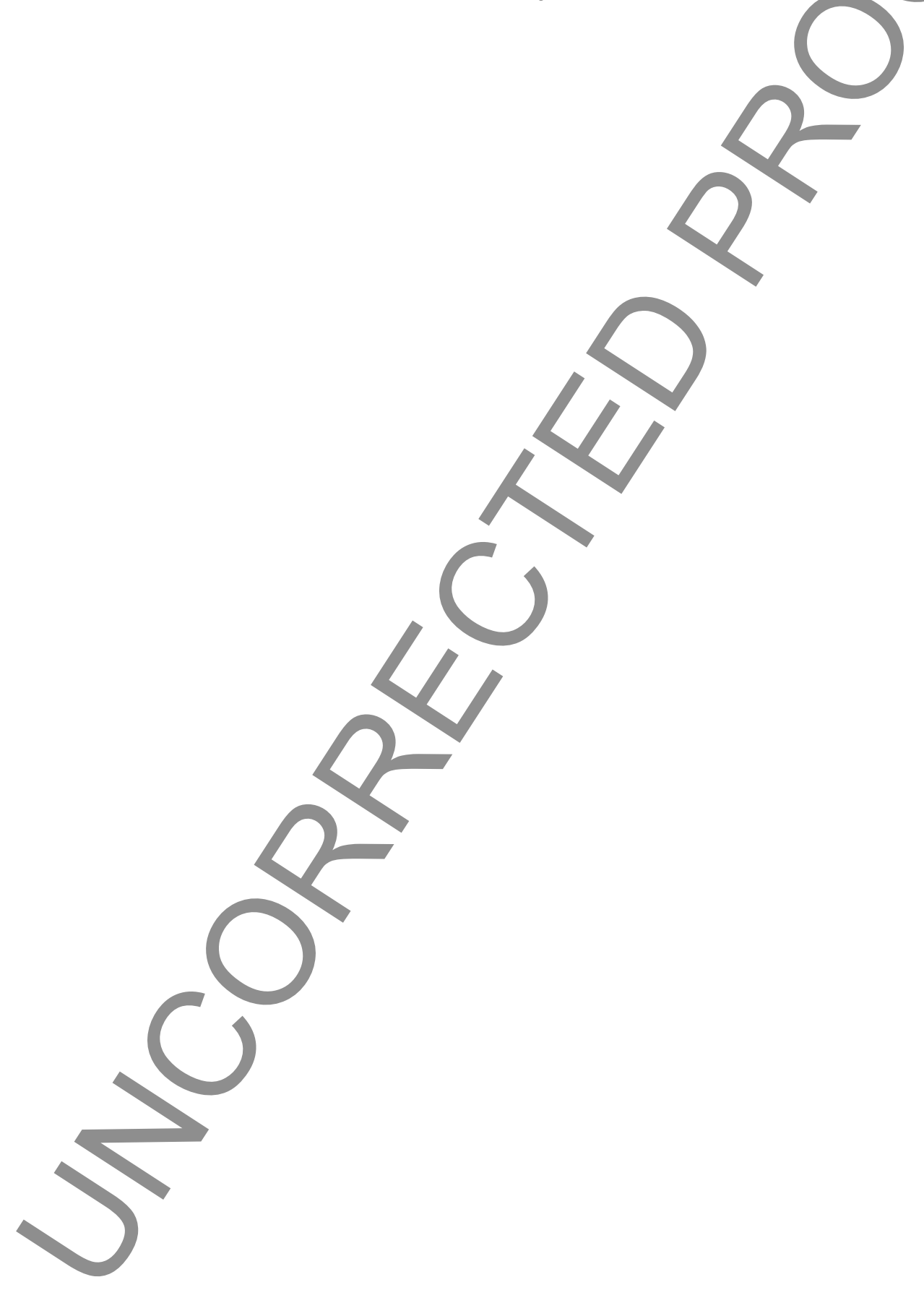

